\title{
Reproductive habits of the so-iuy mullet Liza haematocheilus (Temminck \& Schlegel, 1845) from the Azov-Black sea basin
}

\author{
Leonid Bugaev ${ }^{1,{ }^{*}}$, Efim Kozhurin $^{1}$, Anna Wojkina $^{1,2}$, Anna Neydorf $^{2}$, Svetlana \\ Ponomareva $^{2}$, Anastasiya Olshevskaya ${ }^{2}$, and Marina Egyan ${ }^{2}$ \\ ${ }^{1}$ Azov-Black Sea Branch of the FSBSI « Russian Federal Research Institute of Fisheries and \\ Oceanography» (“AzNIIRKH”) Beregovaa, 344002, 21, Rostov on Don, Russia \\ ${ }^{2}$ Don State Technical University, 344003, Gagarin sq. 1, Rostov on Don, Russia
}

\begin{abstract}
The reproductive system of the female so-iuy mullet Liza haematocheilus (Temminck \& Schlegel, 1845) from the Azov-Black Sea basin has been analyzed regarding the season of observation, fish sex and stages of gonad maturity. The median and percentile values which can be used like control values for formation of qualitative characteristic of variational range of certain individual diameters of oocyte based on the empirical median calculated for this individual were calculated basing on the assessment of variational ranges of the large samples of oocyte of trophoblastic growth. It was demonstrated that in Azov-Black Sea basin's conditions the so-iuy mullet spawning occurs as a single-portioned type except the years with protracted and cold winter. In such conditions is possible a two-portioned spawning.
\end{abstract}

\section{Introduction}

The object of this searching is the so-iuy mullet Liza haematocheilus (Temminck \& Schlegel, 1845) which has become a significant fishing object after its introduction to the Azov-Black sea basin $[1,2]$. Besides, the interest in the so-iuy mullet Liza haematocheilus as in an object of artificial reproduction and commercial aquaculture is significant [3-5].

The acclimatization of all species assumes not only choosing a specific ecological niche, place in the food chain, and physical and chemical characteristics of the habitat and so on, but also a possibility of normal maturation and survival during the sensitive periods of ontogenesis [6 - 8]. The reproductive habits of the so-iuy mullet Liza haematocheilus are of interest. It is explained by the continuation of the process of the so-iuy mullet 's acclimatization to the conditions of the Azov and Black seas. The Peter the Great Gulf in the Sea of Japan in which the so-iuy mullet fingerlings were caught for the introduction differs from Azov and Black seas in indicators of seasonal temperature changes, temperature maximum and salinity of the water. Research has shown that new living conditions have led to certain changes in the physiology and morphology of the species [9].

\footnotetext{
${ }^{*}$ Corresponding author bugaev_1_a@azniirkh.ru
} 
Despite many years of research on various indicators of the so-iuy mullet living in the Azov-Black Sea basin [10], currently there is no generally recognized information in fish farming and fishing about the physiological and biochemical standards of this species in relation to the area of its introduction.

The purpose of this article is to study the dynamics of maturation of the so-iuy mullet gonads in the Azov-Black Sea basin as a reflection of the adaptation strategy on the part of the reproductive system, as well as to determine the quantitative boundaries of oocyte size that can be used in the qualitative assessment of the state of individual in relation to the conditions of the Azov-black sea basin.

\section{Materials and methods}

The results of the research were obtained from samples of fish caught from 2001 to 2018 in the Azov Sea basin during trawl fishing and industrial coastal fishing (the Kerch Strait, the Central part of the Azov sea and the Taganrog Bay). The high migration activity of the soiuy mullet suggests that there is no differentiation into subpopulations in the sea of Azov, and thus there is no need to separate fish depending on the place of catch. In autumn prewintering season fishing was hold from late October to early December, in early spring season it was hold from late March to early April, and during the spawning run it was hold from late May to early June.

The total number of studied fish was 836 individuals. A brief description of fish samples depending on the studied period of life, sex, and stage of gonad maturity is presented in table 1. Physiological and biochemical parameters were evaluated in fish ranging in size from $18 \mathrm{~cm}$ (two-year-olds) to $68 \mathrm{~cm}$ (nine-year-olds).

Table 1. General characteristics of the fish in different periods of their life cycles

\begin{tabular}{|c|c|c|c|c|c|}
\hline Period of life & Sex & $\begin{array}{c}\text { Gonad } \\
\text { maturity stage }\end{array}$ & Number, pcs & $\begin{array}{c}\text { Length, cm } \\
\qquad M \pm S_{x}\end{array}$ & $\begin{array}{c}\text { Weight, } \mathrm{g} \\
M_{ \pm} \boldsymbol{S}_{x}\end{array}$ \\
\hline \multirow{4}{*}{ Pre-wintering period } & \multirow[t]{2}{*}{ Males } & II & 54 & $44.8 \pm 6.61$ & $1528 \pm 743$ \\
\hline & & III & 58 & $50.0 \pm 4.78$ & $2222 \pm 722$ \\
\hline & \multirow{2}{*}{ Females } & II & 73 & $45.5 \pm 10.15$ & $1766 \pm 1004$ \\
\hline & & III & 49 & $49.4 \pm 8.92$ & $2535 \pm 1168$ \\
\hline \multirow{4}{*}{ After wintering } & \multirow{2}{*}{ Males } & II & 51 & $42.0 \pm 7.62$ & $1417 \pm 787$ \\
\hline & & III & 48 & $48.9 \pm 5.26$ & $1848 \pm 770$ \\
\hline & \multirow{2}{*}{ Females } & II & 49 & $38.8 \pm 10.07$ & $1217 \pm 831$ \\
\hline & & III & 52 & $49.8 \pm 5.57$ & $2119 \pm 992$ \\
\hline \multirow{6}{*}{ Pre-spawning period } & \multirow{3}{*}{ Males } & III & 51 & $44.4 \pm 5.90$ & $1342 \pm 642$ \\
\hline & & IV & 102 & $45.9 \pm 5.02$ & $1532 \pm 560$ \\
\hline & & $\mathrm{V}$ & 49 & $49.6 \pm 5.68$ & $2046 \pm 940$ \\
\hline & \multirow{3}{*}{ Females } & III & 52 & $45.8 \pm 5.59$ & $1611 \pm 808$ \\
\hline & & IV & 95 & $48.6 \pm 6.41$ & $2026 \pm 976$ \\
\hline & & $\mathrm{V}$ & 53 & $47.5 \pm 6.70$ & $2346 \pm 1022$ \\
\hline
\end{tabular}

Note: $M$ is the average value of the parameter, $S_{x}$ is the standard deviation. 
The diameter of oocyte was evaluated microscopically at 40 times magnification. The size range of oocytes was calculated for 30-45 females in each of the observation seasons. Each female was measured for 150-200 oocytes of different sizes. The stages of maturity of the gonads of females and males were determined according to the scale proposed by E. B. Moiseeva and A. K. Lyubomudrov [9].

Mathematical data processing was performed by use of specialized software: MS Excel V. 13, Statsoft Statistica V. 12.

\section{Results and discussion}

Fish gonads are in constant development that is why they are integral reflection of individual's condition in general. The gonads condition, their morphology and maturity stage are influenced by:

- environmental factors (temperature, oxygenation, salinity, pollution and etc.)

- biological factors (population density, food composition and nutrition, interspecific and intraspecific relationships and etc.)

- internal organism's factors (the level of plastic and energy reserves, hormonal status, age, weight, health status and etc.)

It should be noted that the condition of the reproductive system of individuals determines the state of the whole organism (organism level), and reproductive capacity of the population (population level).

The adaptive features of the reproductive system of the so-iuy mullet from the AzovBlack Sea basin have been studied in detail, but, as the analysis of literature data shows, the results obtained by different researchers are quite heterogeneous, and sometimes contradictory $[11,12]$.

The differences in habitat parameters between the Azov-Black Sea basin and the Peter the Great Bay in terms of seasonal changes in temperature, temperature maximum, and water salinity led, as studies have shown, to certain changes in the physiology and morphology of the species. It was shown that the higher temperature background of the Azov and Black seas caused an increase in growth paces and a decrease in the age of first maturation by an average of 1-2 years. The adaptation to the Azov-Black sea conditions was resulted in the size heterogeneity of mature eggs, as well as in a decrease in the average size of oocytes compared to the far eastern population [13]. There is information about the portionality of gonad maturation in females caught off the black sea coasts of the Caucasus and Crimea.

Our studies have shown that at the beginning of winter, $25 \%$ of females had gonads at a maturity stage II-III and $75 \%$ of females at a maturity stage III [17]. Starting from the autumn period, the gonads of female of the so-iuy mullet contain oocytes of two generations: reserve and current production fund (Fig. 1). The first oocytes do not mature during the current season and remain at the stage of protoplasmic growth; the diameter of these oocytes is 30-140 microns. It is suggested that they are a reserve for reproduction of the next period. Oocytes of the second group stand out by their size and are more mature, being the expenditure fund of the current spawning; the diameter of oocytes varies within 160-450 microns (Fig. 2). Fishes overwinter, having gonads at II, II-III and III stages of maturity. During the winter period, depending on the temperature, the development of gonads either stops or goes at a slow pace. 


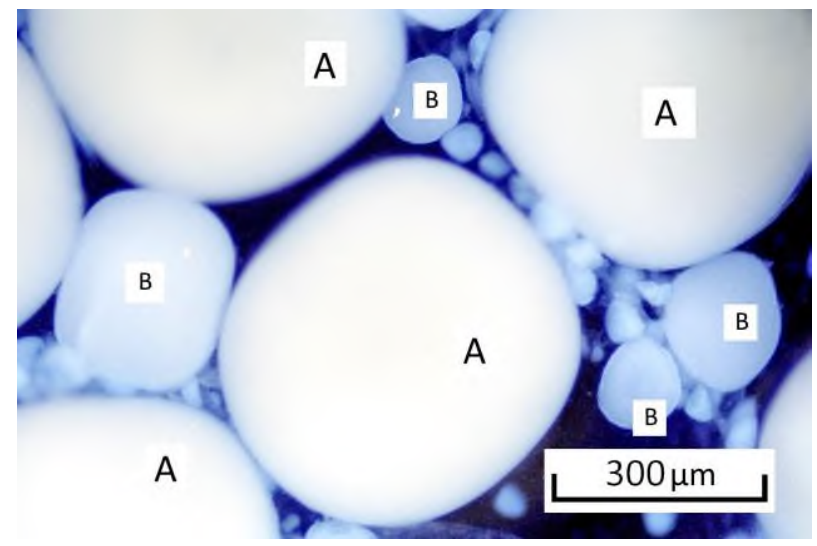

Fig. 1. Micrograph of the so-iuy mullet oocytes. Gonads at maturity stage II-III. 40x magnification A - trophoplasmatic growth of an oocyte (stage III), B - protoplasmatic growth of an oocyte (stage II)

The features of maturation of the female so-iuy mullet in the spring and early summer periods are described in detail in a number of works. It was shown that oocytes from both populations increase in size by mid-March. Oocytes of the reserve fund stop growing, reaching the size of 150-250 microns; the group of trophoplasmic oocytes is represented by cells of different sizes without a pronounced modality. In our research, it was found that oocytes of trophoplasmic growth ae characterized by different sizes (225-450 microns) with pronounced mono- or bimodality. On average, for the entire sample of the so-iuy mullet caught in late March - early April, the modal group of trophoplasmic oocytes is in the range of 300-400 microns (Fig. 2). The majority of females during this period had gonads at a maturity stage III.

The amount of protein and lipids in muscle tissue, gonads, and liver is considered as an indicator of plastic metabolism in fish. In the pre-winter period, the level of protein and fat accumulation in muscle tissue depends on the degree of gonad maturity. It was found that both males and females of pilengas with gonads of the third stage of maturity had higher values of protein and fat accumulation than individuals with gonads of the second stage of maturity. Thus, the best conditions for feeding and accumulation of reserve substances have a positive effect on the rate of maturation of sexual products by the beginning of the winter season.

By the early spring period, the amount of plastic reserves in fish muscle tissue decreases compared to autumn; the dynamics of the decline in indicators continues to the beginning of the spawning period when comparing fish with the same stage of maturity.

The content of total protein in the gonads of females in the pre-winter period significantly exceeds these indicators in males, regardless of the current stage of maturity. At the end of winter, there are no differences in this indicator between females and males when comparing individuals with the same stage of gonad maturity. At the same time, males and females in the III stage of maturity show higher values compared to individuals in the II stage of maturity. In the pre-spawning period, the total protein content in the gonads of females exceeds that of males by almost three times, regardless of the level of gonad maturity. A similar ratio between females and males in the pre-spawning period is noted for the content of total lipids in the gonads. 
November-December

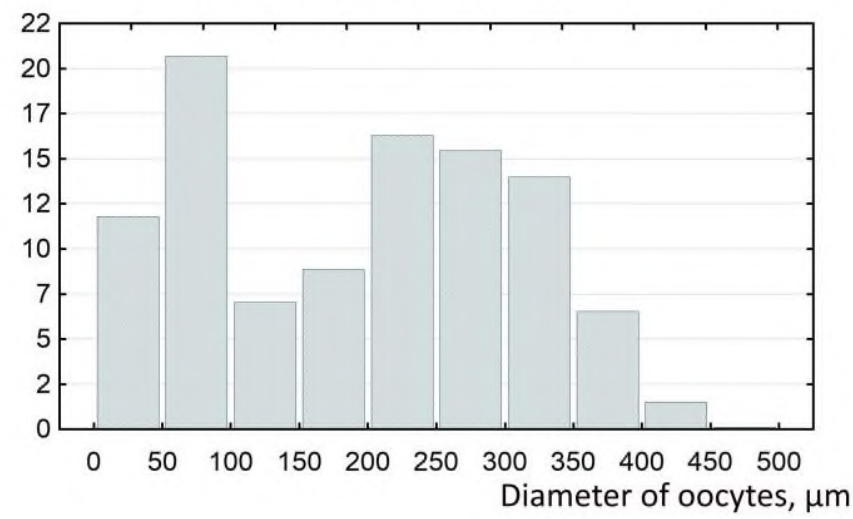

March

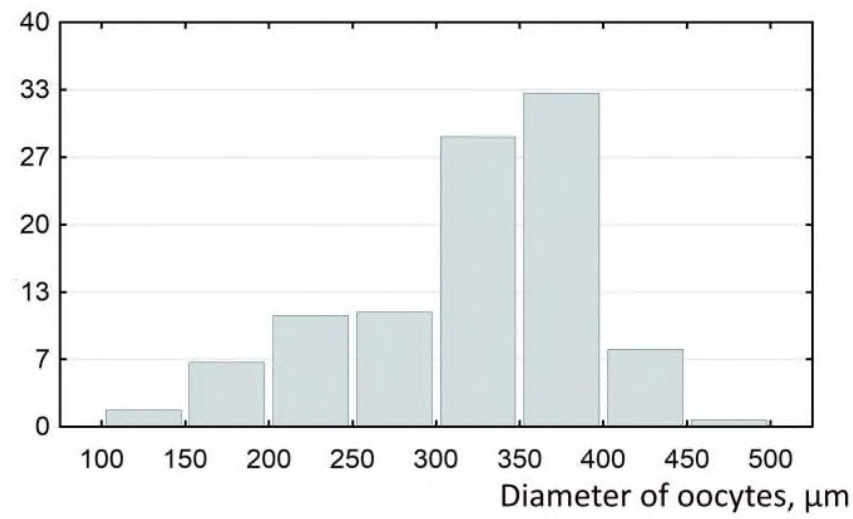

May

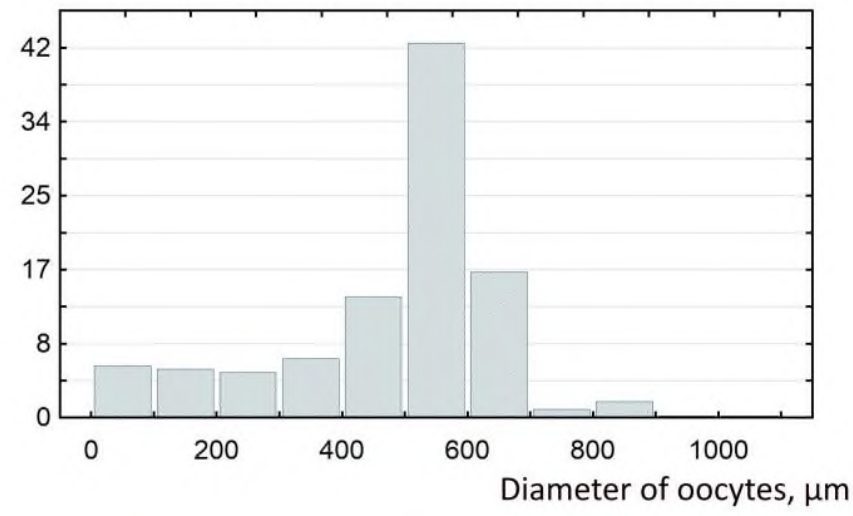

Fig. 2. Size composition of the so-iuy mullet oocytes during various observation seasons

The formation of the expenditure fund of germ cells occurs by the so-iuy mullet in the background of an increase in water temperature in a relatively short period of time, lasting 20-40 days starting from the second decade of May. By the end of May, oocytes in ovaries of the so-iuy mullet are represented by populations of 150-250 microns and 500-700 
microns with a single modal size of 500-600 microns. The majority of females during this period had gonads at a maturity stage III-IV. It should be noticed that in particular years, according to our data, up to $60 \%$ of maturing females with a bimodal distribution of oocyte diameters were detected; the distance between modes was 50 microns. As a specimen of the bimodal distribution of maturing oocytes, we present a female so-iuy mullet caught in the Temryuk Bay on June 1, 2015 (Fig.3).

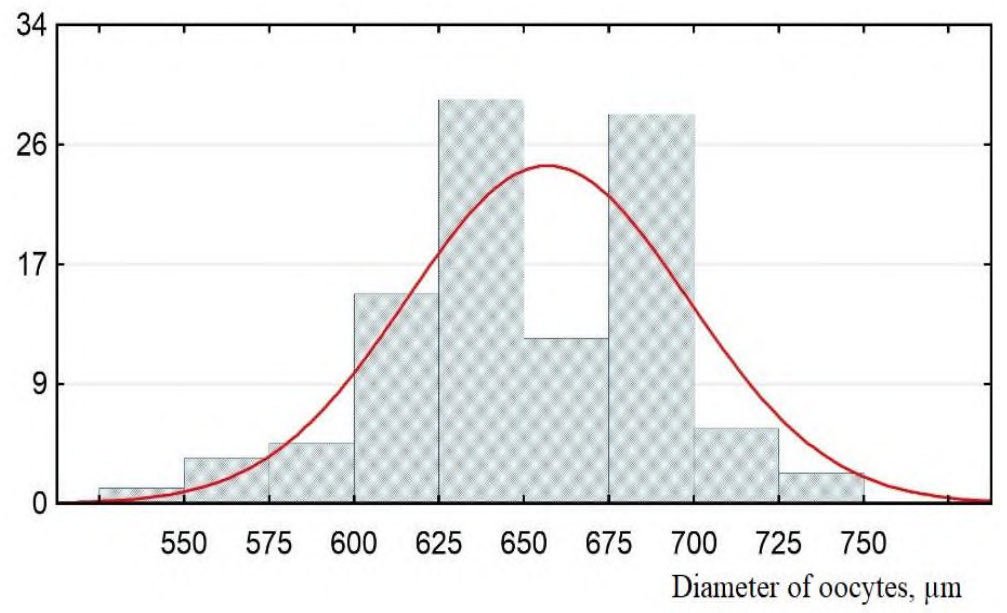

Fig. 3. An example of a bimodal distribution of the oocyte diameter in the so-iuy mullet female (gonads at maturity stage III-IV), caught in the Temryuk Bay on June 1, 2015

As one of the characteristics of the general state of the fish reproductive system in the aspect of preparation for spawning, it would be useful to evaluate the set of oocytes of trophoplasmic growth. Due to the fact that such oocytes, even in one individual, can differ significantly in diameter and have a distribution different from the normal one, it is impossible to operate with averaged sample parameters. In addition, not a single point measurement is analyzed, but a set of measurements. We believe that in this case, the values of the median and percentiles calculated on large samples will be more indicative, and their further use as control values for forming a qualitative characteristic of the variation range of oocyte diameters of a particular individual based on the empirical median calculated for this individual. The proposed reference values of the characteristics of the variation range of the so-iuy mullet oocytes are presented in table 2.[19-20]

Table 2. A variation range of diameters of Mullet oocytes at the throphoplasmic growth stage in different seasons of observation $(\mu \mathrm{m})$

\begin{tabular}{|c|c|c|c|c|c|c|c|c|c|c|c|c|}
\hline Period of life & $\boldsymbol{N}$ & $\boldsymbol{M}$ & $\boldsymbol{S}_{\boldsymbol{x}}$ & $\boldsymbol{P}_{\boldsymbol{1 0}}$ & $\boldsymbol{P}_{\mathbf{2 0}}$ & $\boldsymbol{P}_{\mathbf{3 0}}$ & $\boldsymbol{P}_{\boldsymbol{4 0}}$ & $\boldsymbol{M e}$ & $\boldsymbol{P}_{\mathbf{6 0}}$ & $\boldsymbol{P}_{\mathbf{7 0}}$ & $\boldsymbol{P}_{\boldsymbol{8 0}}$ & $\boldsymbol{P}_{\boldsymbol{9 0}}$ \\
\hline $\begin{array}{c}\text { Pre-wintering } \\
\text { period }\end{array}$ & 3898 & 258 & 81 & 140 & 190 & 210 & 240 & 260 & 280 & 310 & 330 & 360 \\
\hline After wintering & 2720 & 329 & 70 & 220 & 260 & 300 & 340 & 350 & 360 & 370 & 390 & 400 \\
\hline $\begin{array}{c}\text { Pre-spawning } \\
\text { period }\end{array}$ & 4439 & 516 & 145 & 260 & 420 & 500 & 530 & 550 & 570 & 590 & 610 & 650 \\
\hline
\end{tabular}

Note: $N$ - number of oocytes, pcs, $M$ is the average value of the parameter, $S x$ is the standard deviation, $M e$ is the median, $P_{10}, P_{20}, P_{30}, P_{40}, P_{60}, P_{70}, P_{80}, P_{90}$ are percentiles of corresponding percentages 
There are still some discrepancies regarding the structure of the reproductive cycle of the male so-iuy mullet related to the early stages of maturity. According to studies by E. B. Moiseeva and A. K. Lyubomudrov, the second stage of maturity occurs by males from August to February-March. The transition to stages II-III and III begins in mid-January. The results of other studies $[13,14]$ demonstrate that males at II-III and III stages of gonad maturity are caught in late November-early December, and in the total mass the number of such males dominates. These data coincide with observations of the far eastern so-iuy mullet. Males caught in mid-and late March, both in the open sea and in the coastal zone, have synchronously maturing stage III gonads. With an increase of the water temperature from $9.6-11{ }^{\circ} \mathrm{C}$ (April) to $15.5-16.8^{\circ} \mathrm{C}$ (May), rapid maturation of sexual products occurs [15]. By the end of May, most producers have gonads at a maturity stage IV. In the native habitat, most males during this period have gonad at maturity stage III. Many authors note that in the Azov-Black sea area there is a one-time maturation of gonads without signs of asynchrony. It provides a full-fledged spawning of a short-term type in the conditions of rapid increase in water temperature in early-mid-June. By the so-iuy mullet from the Far East, the asynchronous development of germ cells at the final stages of spermatogenesis, as well as the catching-up wave of spermatogenesis, were described. [16-17]

So, the so-iuy mullet acclimatized in the Azov-Black Sea basin has certain adaptive changes in the reproductive cycle caused by new environmental conditions for it, compared to one in the Peter the Great Bay. Females from the Azov-Black Sea basin mature at the same time, signs of asynchrony are observed occasionally. High rates of increase in water temperature during the beginning of summer led to adaptive one-time maturation of males. Nevertheless, with a pronounced change in habitat conditions in the form of cooling in the spring pre-spawning period, there were cases of asynchronous maturation of male gonads, characteristic of the far eastern habitat. [18]

\section{Conclusion}

An important characteristic of the state of a population of any species is its ability to reproduce. The studies have shown that the acclimatization of the so-iuy mullet in the Azov-Black Sea basin led to a number of adaptive changes in the reproductive cycle, which provided the population with the ability to reproduce itself. It is revealed that the spawning of the so-iuy mullet in the conditions of the Azov-Black Sea basin proceeds by singleportioned type: females and males mature at the same time, signs of asynchrony are observed in cold and protracted spring, when a two-portioned spawning is possible. This reproductive strategy differs from the features of multiportional spawning in the native range in the Peter the Great Bay basin.

The study presents control indicators of the variation ranges of oocyte diameters in different periods of the life cycle of females. The qualitative characteristics of the state of the so-iuy mullet female based on the assessment of oocyte diameters depend on the analyzed stage of the life cycle: in the pre-winter period and early spring, the median of the variation ranges characterizes the amount of body resources spent on trophoplasmic growth of oocytes and reflects the quality of feeding; in the pre-spawning and spawning periods, the oocyte diameter characterizes the reproductive qualities of the female. The calculated control indicators can be used in breeding work with the so-iuy mullet female in conditions of artificial reproduction and aquaculture, as well as in assessing the state of producers from natural populations.

It is still an unsolved issue whether the obtained values of reference intervals can be used in the practice of the so-iuy mullet aquaculture grown in the installations of closedcircuit water supply using artificial feed. 


\section{References}

1 P. Thomas, The Journal of Steroid Biochemistry and Molecular Biology, 167, 153-161 (2017) doi.org/10.1016/j.jsbmb.2016.12.005

2 E. Lubzensa, J. Bobe, Aquaculture, 472, 107-143 (2017) doi.org/10.1016/j.aquaculture.2016.10.029

3 K. Ganias, S. K. Lowerre-Barbierib, Journal of Sea Research, 96, 1-10 (2015) doi.org/10.1016/j.seares.2014.10.018

4 T. Ziva, T. Gattegno, Comparative Biochemistry and Physiology Part D: Genomics and Proteomics 12-35 (2017) doi.org/10.1016/j.cbd.2017.06.004

5 M. Fabra, D. Raldú, Yolk proteolysis and aquaporin-1o play essential roles to regulate fish oocyte hydration during meiosis resumption Developmental Biology, 295(1), 250262 (2006)

6 S. Liang, W. Wang, Aquaculture, 528, $735 \quad$ - $743 \quad$ (2020) doi.org/10.1016/j.aquaculture.2020.

7 B. Loia, I. Antonios, Papadakis Aquaculture, 526, 178-184 (2020)

8 S. Song, Fish \& Shellfish Immunology, 90, 102-108 (2019) doi.org/10.1016/j.fsi.2019.04.299

9 W. Wei, N. Cuijuan, Comparative Biochemistry and Physiology Part C: Toxicology \& Pharmacology, 148, 466 (2010) doi.org/10.1016/j.cbpc.2010.10.068

10 M. L. Urich, M. L. Henderson, Comparative Biochemistry and Physiology Part B: Biochemistry and Molecular Biology, 250 doi.org/10.1016/j.cbpb.2020.110491

11 G. Silvera, I. Gomez, Marine Environmental Research 156, 161-167 (2020) doi.org/10.1016/j.marenvres.2020.104902

12 A. Pandey, Ecotoxicology and Environmental Safety, 15, 221-225 (2018) doi.org/10.1016/j.seares.2018.10.018

13 F. da Silva, C. Jacobsen, Aquaculture, 496, 30-38 (2018) doi.org/10.1016/j.aquaculture.2018.07.008

14 M. Moura, F. F. Paula-Lopes, Theriogenology, 156, 262-271 (2020) doi.org/10.1016/j.theriogenology.2020.06.017

15 H. Kalamarz-Kubiak, T. Guellard, Oceanologia, 61, 534-539 (2019) doi.org/10.1016/j.oceano.2019.06.001

16 M. Mazanko, E. Prazdnova, D. Rudoy, A. Ermakov, A. Olshevskaya, T. Maltseva, E3S Web of Conferences, 175, 01010 (2020) INTERAGROMASH 2020 https://doi.org/10.1051/e3sconf/202017501010

17 E. Zubrilina, I. Markvo, V. Novikov, A. Beskopylny, L. Vysochkina, D. Rudoy, A. Butovchenko, IOP Conf. Series: Earth and Environmental Science, 403, 012063 (2019) IOP Publishing doi:10.1088/1755-1315/403/1/012063

18 A. Altybayev, Y. Naydenko, B. Meskhi, A. Mozgovoy, D. Rudoy, A. Olshevskaya, E3S Web of Conferences, 175, 03019 (2020) INTERAGROMASH 2020 https://doi.org/10.1051/e3sconf/202017503019

19 V. V. Ivanov, S. I. Popov, E. M. Selemeneva, N. T. Babazhanov, Study of technological characteristics of the process of formation of vibration mechanochemical oxide coating, XV International scientific-technical conference «Dynamics of technical systems» (DTS-2019): AIP Conference Proceedings, 2188, 020015 (2019) doi.org/10.1063/1.5138389 
20 V. V. Ivanov, S. I. Popov, A. V. Kirichek, Investigation of optimal chemical composition of cast aluminum alloys for vibrational mechanical-chemical polishing and deposition of protective and decorative coatings, XI International Conference on Mechanical Engineering, Automation and Control Systems (MEACS 2017): IOP Conference Series: Materials Science and Engineering, 327, 032026 (2018) doi:10.1088/1757-899X/327/3/032026 